Buletin Ilmiah Math, Stat, dan Terapannya (Bimaster)

Volume 08, No. 1 (2019), hal 1-10.

\title{
PREDIKSI NILAI TUKAR DOLAR AMERIKA SERIKAT TERHADAP RUPIAH DENGAN METODE SUPPORT VECTOR REGRESSION (SVR)
}

\author{
Sriyana, Shantika Martha, Evy Sulistianingsih
}

INTISARI

\begin{abstract}
Support Vector Regression (SVR) merupakan salah satu metode yang digunakan dalam peramalan data linier dan non linier dengan bantuan fungsi kernel. Pada penelitian ini, metode SVR digunakan untuk memprediksi nilai tukar dolar Amerika Serikat terhadap rupiah. Data nilai tukar jual harian dolar Amerika terhadap rupiah yang berjumlah 445 hari telah dibagi menjadi dua bagian, yaitu 415 data training dan 30 data testing. Data tersebut merupakan data sekunder yang diperoleh dari web resmi Bank Indonesia dari periode 4 Januari 2016 sampai 29 September 2017. Data training digunakan untuk mengestimasi parameter model pada metode SVR dan data testing digunakan sebagai pembanding hasil prediksi. Dari hasil penelitian, parameter SVR yang diestimasi menghasilkan hasil prediksi yang bersesuaian dengan data training dengan nilai $R^{2}$ bernilai 0,9223 dan RMSE bernilai 54,3156. Selain itu, hasil estimasi parameter model pada metode SVR yang dihasilkan mampu untuk memprediksi nilai tukar jual harian dolar Amerika terhadap rupiah yang dikomparasi dengan data testing dengan nilai nilai $R^{2}$ bernilai 0,5397 dan RMSE bernilai 66,8015.
\end{abstract}

Kata Kunci : Lagrange, RMSE, $R^{2}$, Estimasi Parameter, Training, Testing, Kernel

\section{PENDAHULUAN}

Nilai tukar dolar terhadap rupiah terus berubah setiap waktu. Perubahan nilai tukar rupiah terhadap dolar ini berdampak pada kondisi harga barang elektronik yang diimpor dari luar negeri sehingga akan mempengaruhi perekonomian dalam negeri. Perbedaan nilai tukar mata uang suatu negara (kurs) pada prinsipnya ditentukan oleh besarnya permintaan dan penawaran mata uang tersebut.

Nilai tukar mata uang merupakan salah satu variabel ekonomi makro yang sangat penting, karena pergerakan nilai tukar mata uang dapat mempengaruhi stabilitas ekonomi. Tingginya permintaan dan penawaran dalam negeri terhadap komoditi barang dan jasa yang tersedia di luar negeri mengharuskan suatu negara melakukan hubungan internasional dengan negara lain. Dari hasil prediksi terhadap nilai tukar dolar terhadap rupiah perlu dilakukan untuk mengantisipasi kenaikan nilai tukar dolar yang semakin meninggi terhadap rupiah. Salah satu caranya dengan menyarankan beberapa kebijakan terhadap pemerintah agar trend nilai tukar dolar menurun terhadap rupiah. Contoh dari kebijakan tersebut adalah dengan melakukan revaluasi (menaikkan mata uang dalam negeri atas mata uang asing), sehingga mata uang rupiah dapat memiliki nilai yang tinggi.

Support Vector Regression (SVR) merupakan algoritma machine learning yang dapat mengenali pola dari data time series serta dapat memberikan hasil prediksi yang baik jika nilai dari parameter pentingnya dapat ditentukan [1]. Selain itu, metode ini dapat mengatasi kasus non linier dan overfitting yang terdapat pada prediksi nilai tukar dolar Amerika terhadap rupiah ini. Penelitian ini bertujuan untuk mengestimasi parameter model pada metode Support Vector Regression (SVR). SVR merupakan model regresi dari algoritma Support Vector Machine (SVM) yang digunakan untuk memprediksi nilai tukar dolar Amerika terhadap rupiah.

Metode SVR ini sudah banyak digunakan dalam berbagai kasus, metode Support Vector Regression (SVR) dengan Particle Swarm Optimization (PSO) telah digunakan untuk memprediksikan harga saham [2]. Metode SVR juga digunakan dalam memprediksikan kurs rupiah terhadap dolar Amerika serikat dengan menggunakan fungsi kernel linier dan polinomial [3]. Berbeda 
dari penelitian sebelumnya, pada penelitian ini digunakan metode SVR dengan bantuan kernel RBF (Radial Basis Function) untuk memprediksikan nilai tukar dolar Amerika terhadap rupiah dengan ukuran akurasi yang digunakan adalah RMSE (Root Mean Square Error) dan $\mathrm{R}^{2}$ (Koefisien Determinasi).

\section{QUADRATIC PROGRAMMING}

Faktor $\|\boldsymbol{w}\|^{2}$ dinamakan faktor regularisasi (keteraturan). Meminimalkan $\|\boldsymbol{w}\|^{2}$ membuat suatu fungsi setipis mungkin sehingga bisa mengontrol kapasitas fungsi. Faktor kedua dalam fungsi tujuan adalah kesalahan empiris (empirical error) yang diukur dengan $\varepsilon$-insensitive loss function. Menggunakan ide $\varepsilon$-insensitive loss function harus meminimalkan norm dari $\boldsymbol{w}$ agar mendapatkan generalisasi (parameter umum) yang baik untuk fungsi regresi $f$. Oleh karena itu, perlu dilakukan penyelesaian masalah optimasi berikut:

$$
\min \frac{1}{2}\|\boldsymbol{w}\|^{2}
$$

yang dipenuhi dan dibatasi oleh:

$$
\begin{gathered}
y_{i}-\boldsymbol{w}^{T} \boldsymbol{\varphi}(x)-b \leq \varepsilon, \text { dengan } i=1,2, \ldots n \\
\boldsymbol{w}^{T} \boldsymbol{\varphi}(x)-y_{i}+b \leq \varepsilon, \text { dengan } i=1,2, \ldots n \\
\sum e^{2}=\sum(y-\hat{y})^{2}=\sum\left(y-\left(b_{0}+b_{1} x\right)\right)^{2}
\end{gathered}
$$

Diasumsikan bahwa ada suatu fungsi $f$ yang dapat mengaproksimasi semua titik $\left(x_{i}, y_{i}\right)$, dengan presisi (ketepatan) $\varepsilon$. Pada kasus ini diasumsikan bahwa semua titik terdapat dalam rentang $f \pm \varepsilon$ (feasible). Dalam hal ketidaklayakan (infeasible), mungkin terdapat beberapa titik keluar dari rentang $f \pm \varepsilon$, dengan menambahkan variabel slack $\xi$ dan $\xi^{*}$ untuk mengatasi masalah pembatas yang tidak layak (infeasible constraint) pada masalah optimasi.

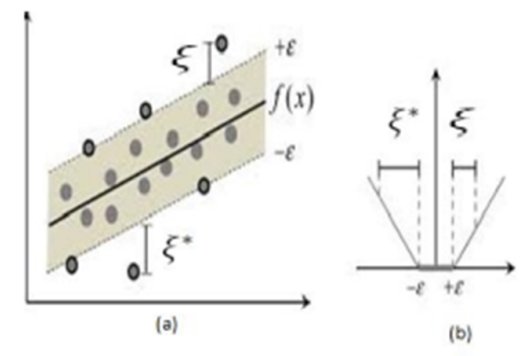

Gambar 1 (a) Output SVR (b) $\varepsilon$ - Insensitive Loss Function

Selanjutnya, masalah optimasi pada Gambar 1 bisa diformulasikan sebagai berikut :

$$
\min \frac{1}{2}\|\boldsymbol{w}\|^{2}+C \frac{1}{n} \sum_{i=1}^{n}\left(\xi_{i}, \xi_{i}^{*}\right)
$$

yang dipenuhi dan dibatasi oleh:

$$
\begin{gathered}
y_{i}-\boldsymbol{w}^{T} \boldsymbol{\varphi}(x)-b-\xi_{i} \leq \epsilon, \text { dengan } i=1,2, \ldots n \\
\boldsymbol{w}^{T} \boldsymbol{\varphi}(x)-y_{i}+b-\xi_{i}{ }^{*} \leq \epsilon, \text { dengan } i=1,2, \ldots n \\
\xi_{i}, \xi_{i}{ }^{*} \geq 0
\end{gathered}
$$

\section{FUNGSI LAGRANGE DAN LAGRANGE MULTIPLIER}

Konstanta $\mathrm{C}>0$ menentukan trade off (tawar menawar) antara kedekatan fungsi $f$ dan batas atas deviasi lebih dari $\varepsilon$ masih ditoleransi. Semua deviasi lebih besar dari $\varepsilon$ dikenakan pinalti sebesar $\mathrm{C}$. Pada SVR, $\varepsilon$ setara dengan akurasi dari aproksimasi (pendekatan) terhadap data training. Nilai $\varepsilon$ yang kecil terkait dengan nilai yang tinggi pada variabel slack $\xi_{i}$ dan akurasi (ketepatan) aproksimasi yang 
tinggi. Sebaliknya, nilai yang tinggi untuk $\varepsilon$ berkaitan dengan nilai variabel $s l a c k \xi_{i}$ yang kecil dan aproksimasi yang rendah. Jika dilihat pada Persamaan (2) nilai yang tinggi untuk variabel slack membuat kesalahan empiris mempunyai pengaruh yang besar terhadap faktor regularisasi. Pada SVR, Support Vector merupakan data training yang terletak pada dan di luar batas $f$ dari fungsi keputusan, karena itu jumlah Support Vector menurun dengan naiknya $\varepsilon$ [4].

Fungsi Lagrange digunakan untuk mengoptimasi Lagrange multiplier agar didapatkan model yang baik [5]. Masalah optimasi dari SVR dapat diselesaikan dengan fungsi Lagrange berikut :

$$
\begin{aligned}
Q\left(w, b, \xi, \xi^{*}, \alpha, \alpha^{*}, \eta, \eta^{*}=\right. & L \\
= & \frac{1}{2}\|w\|^{2}+C \sum_{i=1}^{n}\left(\xi_{i}+\xi_{i}^{*}\right) \\
& -\sum_{i=1}^{n} \alpha_{i}\left(\varepsilon+\xi_{i}-y_{i}+\boldsymbol{w}^{T} \varphi(\boldsymbol{x})+b\right) \\
& -\sum_{i=1}^{n} \alpha_{i}^{*}\left(\varepsilon+\xi_{i}^{*}+y_{i}-\boldsymbol{w}^{T} \varphi(\boldsymbol{x})-b\right) \\
& -\sum_{i=1}^{n}\left(\eta_{i} \xi_{i}+\eta_{i}^{*} \xi_{i}^{*}\right)
\end{aligned}
$$

$L$ dinamakan fungsi Lagrange, $\eta_{i}, \eta_{i}^{*}, \alpha_{i}, \alpha_{i}^{*}$ adalah Lagrange Multiplier. Dengan melakukan turunan parsial pada $L$ terhadap $\boldsymbol{w}, b, \xi, \xi^{*}$ maka akan didapatkan solusi optimal. Solusi optimal untuk $\boldsymbol{w}$ dituliskan sebagai berikut:

$$
\boldsymbol{w}=\sum_{i=1}^{n}\left(\alpha_{i}-\alpha_{i}^{*}\right) \boldsymbol{\varphi}\left(x_{i}\right)
$$

Dengan menggunakan $\boldsymbol{w}$ pada Persamaan (4) akan didapatkan :

$$
\begin{aligned}
f(x) & =\boldsymbol{w}^{T} \boldsymbol{\varphi}(x)+b \\
& =\sum_{i=1}^{n}\left(\alpha_{i}-\alpha_{i}^{*}\right) \boldsymbol{\varphi}^{T}\left(x_{i}\right) \boldsymbol{\varphi}(x)+b \\
& =\sum_{i=1}^{n}\left(\alpha_{i}-\alpha_{i}^{*}\right) K\left(x_{i}, x\right)+b
\end{aligned}
$$

$K\left(x_{i}, x\right)$ merupakan dot-product kernel yang didefinisikan sebagai berikut:

$$
K\left(x_{i}, x\right)=\varphi^{T}\left(x_{i}\right) \varphi(x)
$$

\section{METODE KERNEL DAN FUNGSI KERNEL}

Teknik pada data mining atau machine learning yang dikembangkan dengan asumsi kelinieran sangat banyak, sehingga untuk kasus-kasus yang linier, algoritma yang dihasilkan terbatas. Dengan metode kernel (Kernel Trick) suatu data $x$ di input space dipetakan ke feature space (ruang koordinat yang dimuati oleh fungsi) dengan dimensi yang lebih tinggi melalui $\boldsymbol{\varphi}$. Jenis-jenis kernel dan fungsinya adalah sebagai berikut [6]:

1) Linier

Fungsi pada linier merupakan fungsi dengan variabel bebas berpangkat satu [7]. Fungsi linier dapat digunakan dalam bentuk kernel yang digunakan sebagai sarana pemetaan. Persamaan fungsi kernel linier adalah,

\section{2) Polynomial}

$$
K(\boldsymbol{x}, \boldsymbol{y})=\boldsymbol{x} \cdot \boldsymbol{y}
$$

Fungsi pada polynomial merupakan fungsi bersuku banyak [7]. Kernel polynomial ini biasa digunakan dalam SVM dan metode kernel lainnya, kernel ini merepresentasikan pemetaan vektor 
menggunakan fungsi polynomial untuk kasus non linier [8]. Persamaan fungsi kernel Polynomial adalah,

3) Radial Basis Fuction (RBF)

$$
K(x, y)=(x \cdot y+c)^{d}
$$

Fungsi RBF merupakan fungsi yang membentuk grafik berbentuk lonceng [7]. Kernel RBF merupakan kernel yang paling sering digunakan karena dengan pemilihan nilai $\sigma$ yang tepat, kernel ini dapat memiliki akurasi yang sama dengan linier dan polynomial. Hal ini menjadikan kernel RBF sebagai kernel yang mewakili kernel lainnya (dapat digunakan dalam berbagai kasus) [9]. Persamaan fungsi kernel RBF adalah,

$$
K(\boldsymbol{x}, \boldsymbol{y})=\exp (-\gamma\|\boldsymbol{x}-\boldsymbol{y}\|)
$$

dengan $\gamma=\frac{1}{2 \sigma^{2}}$

4) Tangent hyperbolic (sigmoid)

Fungsi tangent hyberbolic merupakan fungsi trigonometri hiperbolik yang merupakan hasil kombinasi dari fungsi-fungsi eksponen, fungsi ini memiliki bentuk grafik berbentuk S ketika diplot [10]. Persamaan fungsi kernel sigmoid adalah,

$$
K(\boldsymbol{x}, \boldsymbol{y})=\tanh (\sigma(\boldsymbol{x} \cdot \boldsymbol{y})+c)
$$

dengan $\boldsymbol{x}$ dan $\boldsymbol{y}$ merupakan pasangan dua data dari semua bagian data training, dengan lebih spesifik $\boldsymbol{x}$ merupakan data input dan $\boldsymbol{y}$ merupakan data input data yang ingin memprediksi output. Parameter $\sigma, c, d>0$ merupakan konstanta.

\section{SUPPORT VECTOR REGRESSION (SVR)}

Dalam kasus non linier, SVR merupakan pengembangan dari Support Vector Machine (SVM). SVR adalah salah satu dari kumpulan teknik regresi dan klasifikasi. Metode SVR merupakan pengembangan dari algoritma non linier yang dikembangkan di Rusia pada tahun enam puluhan [4]. Metode ini telah digunakan dalam berbagai aplikasi dan memiliki performa yang baik. Output yang akan dihasilkan dalam kasus regresi berupa bilangan riil dan kontinu. Overfitting data dapat diatasi dengan metode SVR sehingga akan menghasilkan akurasi yang baik [11].

Misalkan terdapat $\mathrm{n}$ set data training, $\left(x_{i}, y_{i}\right)$ dengan $i=1,2, \ldots, \mathrm{n}$ dengan input $x=\left\{x_{1}, x_{2}, x_{3}, \ldots x_{n}\right\}$, dengan output yang dihasilkan $y=\left\{y_{1}, y, y_{3}, \ldots y_{n}\right\}$. Suatu fungsi $f(x)$ yang mempunyai deviasi (simpangan) yang paling besar $\varepsilon$ dari target aktual $y_{i}$ untuk semua data training akan didapatkan dari SVR. Ketika $\varepsilon=0$, regresi yang sempurna didapatkan.

Model SVR yang dituliskan dinyatakan dalam Persamaan (5) dengan $f(x)$ menunjukkan output dari model , $x$ merupakan data input tujuan, $x_{i}$ merupakan data input periode ke- $i, \mathrm{~b}$ merupakan bias, $\alpha_{i}$ dan $\alpha_{i}^{*}$ merupakan pengali tak tentu Lagrange, $K\left(x_{i}, x\right)$ merupakan fungsi kernel hasil pemetaan [12].

\section{Z-SCORE DATA}

Langkah pertama dalam mengestimasi parameter model pada metode SVR adalah melakukan ZScore pada data $x$. Hal ini dilakukan untuk mendapatkan hasil pemodelan yang baik. Z-score mentransformasikan data ke dalam rentang nilai tertentu. Persamaan yang digunakan untuk mendapatkan Z-Score adalah sebagai berikut [13].

$$
\begin{gathered}
Z-\operatorname{Score}(x)=\frac{x-\bar{x}}{s} \\
s=\sqrt{\frac{\sum_{i=1}^{n}\left(x_{i}-\bar{x}\right)^{2}}{n-1}}
\end{gathered}
$$


dengan $x_{i}=y_{i-1}$ merupakan data input ke-i, $\bar{x}$ merupakan rata-rata data input, dan $s$ merupakan standar deviasi data input.

\section{ESTIMASI PARAMETER}

Parameter pertama yang diperlukan untuk peramalan adalah fungsi kernel. Kernel digunakan untuk memetakan suatu data $x$ dari input space ke feature space yang memiliki dimensi lebih tinggi melalui $\boldsymbol{\varphi}(x)$ [6]. Kernel yang digunakan dalam penelitian ini adalah kernel RBF yang bersesuaian dengan penelitian sebelumnya yang meneliti tentang peramalan harga saham menggunakan metode Support Vector Regression (SVR) dengan Particle Swarm Optimization (PSO) [2]:

$$
K\left(x_{i}, x\right)=\exp \left(-\frac{\left\|x_{i}-x\right\|}{2 \sigma^{2}}\right)
$$

dengan $x_{i}$ merupakan data input ke-i, $x$ merupakan data input tujuan, dan $\sigma$ sebagai konstanta.

Parameter kedua yang diperlukan untuk peramalan adalah $\left(\alpha_{i}-\alpha_{i}^{*}\right)$, hal ini disebabkan karena model pada metode SVR mengandung pengali tak tentu Lagrange (Langrange multiplier). Pertidaksamaan yang memenuhi dan membatasi Persamaan (2) digunakan untuk membentuk algoritma SVR [14] untuk mendapatkan nilai $\left(\alpha_{i}-\alpha_{i}^{*}\right)$. Parameter terakhir yang diperlukan adalah bias. Pada beberapa kasus SVR nilai bias yang dipilih bernilai nol $[3,2,14]$, karena nilai $\left(\alpha_{i}-\alpha_{i}^{*}\right)$ dapat menyesuaikan berdasarkan nilai bias yang dipilih dan mempermudah penyusunan coding [11]. Di dalam MATLAB pertidaksamaan yang memenuhi dan membatasi Persamaan (2) diterjemahkan sebagai berikut [14]:

$$
\text { alpha(i) }=\text { alpha(i) }+y(i)-\text { eps*sign }(\operatorname{alpha}(\mathrm{i}))-\text { alpha' } \mathrm{K}\left(\mathrm{x}, x_{i}\right)
$$

dengan alpha(i) yang di sebalah kanan tanda sama dengan $(=)$ adalah nilai alpha yang lama (alpha_old), sedangkan alpha(i) yang di sebelah kiri sama dengan $\left(_{(=)}\right.$adalah nilai alpha yang baru yang didapatkan dari perhitungan.

eps*sign (alpha(i)) $=\xi \operatorname{dan} \xi^{*}($ bergantung pada $\operatorname{sign}($ alpha(i) $))$,

nilai eps $=0,1$ dan $\operatorname{sign}($ alpha(i) $)=-1,0$, atau 1 ,

jika alpha(i) (alpha_old) $<0$, maka nilai $\operatorname{sign}($ alpha(i)) yang disubstitusikan adalah -1

jika alpha(i) $($ alpha_old $)=0$, maka nilai sign(alpha(i)) yang disubstitusikan adalah 0

jika alpha(i) (alpha_old $)>0$, maka nilai sign(alpha(i)) yang disubstitusikan adalah 1

dan alpha(i) $=\left(\alpha_{i}-\alpha_{i}^{*}\right)$,

Kriteria penghentian proses running coding adalah norm(alpha_old-alpha) $<$ tol atau iterasi=maks iterasi. Dengan nilai tol (toleransi) yang digunakan adalah 0,1 . Hal tersebut menjelaskan bahwa proses dihentikan ketika salah satu syarat terpenuhi.

pada kondisi awal alpha merupakan matriks nol.

$$
\text { alpha (alpha_old) }=\left[\begin{array}{c}
\operatorname{alpha}(1) \\
\operatorname{alpha}(2) \\
\operatorname{alpha}(3) \\
\vdots \\
\operatorname{alpha}(N)
\end{array}\right]=\left[\begin{array}{c}
0 \\
0 \\
0 \\
\vdots \\
0
\end{array}\right],
$$

dengan melalui proses iterasi terakhir (iterasi ke-1000) maka bentuk matriks alpha (alpha_old) akan terisi dengan elemen matriks alpha yang baru.

$$
\text { alpha }=\left[\begin{array}{c}
\text { alpha(1) } \\
\operatorname{alpha}(2) \\
\operatorname{alpha}(3) \\
\vdots \\
\operatorname{alpha}(N)
\end{array}\right]=\left[\begin{array}{c}
\left(\alpha_{1}-\alpha_{1}^{*}\right) \\
\left(\alpha_{2}-\alpha_{2}^{*}\right) \\
\left(\alpha_{3}-\alpha_{3}^{*}\right) \\
\vdots \\
\left(\alpha_{N}-\alpha_{N}^{*}\right)
\end{array}\right],
$$




\section{DIAGNOSTIK MODEL}

Setelah melakukan estimasi parameter, selanjutnya dilakukan prediksi nilai tukar jual harian dolar Amerika terhadap rupiah. Hasil dari pemodelan SVR dilakukan pengecekan keakuratan peramalan. Diagnostik model yang dapat digunakan adalah Root Mean Square Error (RMSE) dan koefisien determinasi $\left(\mathrm{R}^{2}\right)$. Diagnostik model dilakukan untuk mengetahui akurasi pada pemodelan data training dan data testing. Data training digunakan dalam mengestimasi parameter, namun biasanya terdapat error dalam pemodelan, sehingga model data training juga perlu untuk diverifikasi kembali. Nilai RMSE dapat dihitung dengan rumus berikut ini [15].

$$
\mathrm{RMSE}=\sqrt{\sum_{i=1}^{n} \frac{\left(y_{i}-\hat{y}_{i}\right)^{2}}{n}}
$$

dengan $\hat{y}_{i}$ merupakan nilai peramalan pada periode $i, y_{i}$ merupakan data aktual pada periode $i$, dan $n$ merupakan jumlah data.

Dan nilai $\mathrm{R}^{2}$ dapat dihitung dengan rumus sebagai berikut [16]:

$$
\mathrm{R}^{2}=\frac{\left[\sum\left(y_{i}-\bar{y}\right)\left(\hat{y}_{i}-\bar{y}\right)\right]^{2}}{\sum\left(y_{i}-\bar{y}\right)^{2} \sum\left(\hat{y}_{i}-\bar{y}\right)^{2}}
$$

dengan $y_{i}$ merupakan data aktual pada periode $i, \bar{y}$ merupakan nilai rata-rata data aktual, dan $\hat{y}_{i}$ merupakan nilai peramalan pada periode $i$. Besarnya nilai $\mathrm{R}^{2}$ adalah $0 \leq \mathrm{R}^{2} \leq 1$, dengan nilai $\mathrm{R}^{2}$ semakin mendekati 1 berarti model tersebut dapat dikatakan baik.

\section{STUDI KASUS}

Pada penelitian ini data yang digunakan merupakan data sekunder, yaitu nilai tukar jual harian dolar Amerika terhadap rupiah. Periode data yang digunakan sebagai data training dalam pembentukan model SVR ini yaitu selama 415 hari dari tanggal 4 Januari 2016 sampai 18 Agustus 2017 yang diperoleh dari Bank Indonesia [17]. Data 30 hari setelahnya digunakan sebagai data testing yang dibandingkan dengan hasil prediksi dari model SVR.

Data yang melewati tahap Z-score adalah data training dan data testing yang merupakan nilai dolar satu hari sebelumnya $\left(x_{i}=y_{i-1}\right)$. Hal ini dilakukan agar mendapatkan model yang baik dan menambah ketepatan dari fungsi regresi SVR. Perhitungan Z-score dilakukan dengan menyelesaikan Persamaan (11). Gambar 2 merupakan grafik hasil dari Z-score dari data training $x$ :

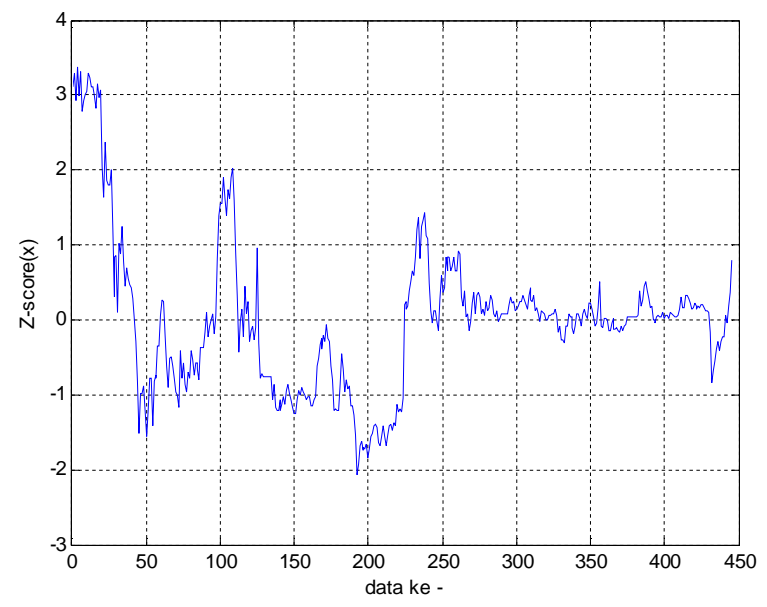

Gambar 2 Grafik $Z$-Score $(x)$ terhadap data ke- $i$ 
Nilai Z-score tersebut akan digunakan sebagai input pada model SVR.

Nilai fungsi kernel $K\left(x_{i}, x\right)$ dihitung menggunakan Persamaan (13). Setiap nilai yang ingin diprediksi memerlukan 415 nilai $K\left(x_{i}, x\right)$. Gambar 3 memperlihatkan nilai $K\left(x_{i}, x\right)$ yang dihitung untuk memprediksi data testing terakhir yaitu data ke-445 yaitu sebanyak 415 nilai $K\left(x_{i}, x\right)$.

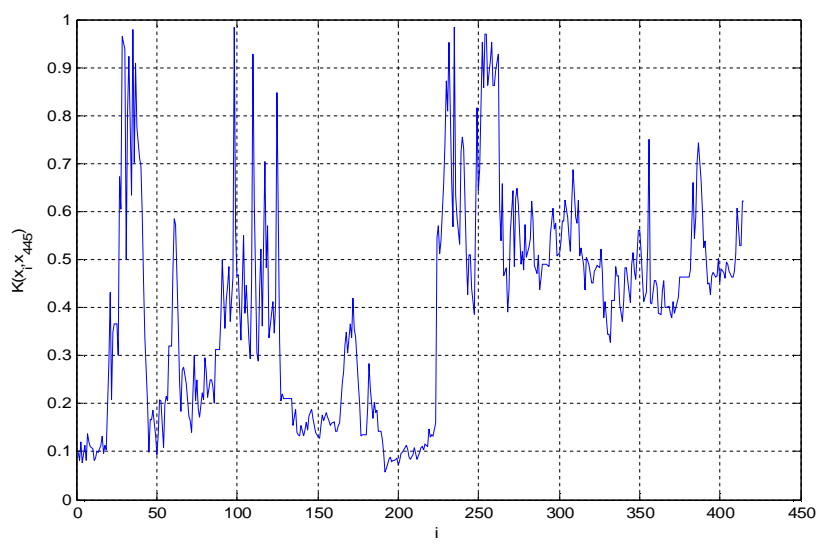

Gambar 3 Grafik Nilai $K\left(x_{i}, x_{445}\right)$ terhadap $i$

Selain $K\left(x_{i}, x\right)$ parameter lain yang diperlukan adalah $\left(\alpha_{i}-\alpha_{i}^{*}\right)$ yang dihitung menggunakan algoritma SVR dengan bantuan software MATLAB [14]. Kernel yang digunakan untuk mendapatkan nilai $\left(\alpha_{i}-\alpha_{i}^{*}\right)$ adalah kernel RBF (Radial Basis Function). Pada penelitian ini digunakan kernel RBF karena kernel RBF paling cocok untuk digunakan pada data fluktuatif (naik turun terhadap waktu seperti yang diperlihatkan pada Gambar (2)) yang dituliskan dalam Persamaan (13).

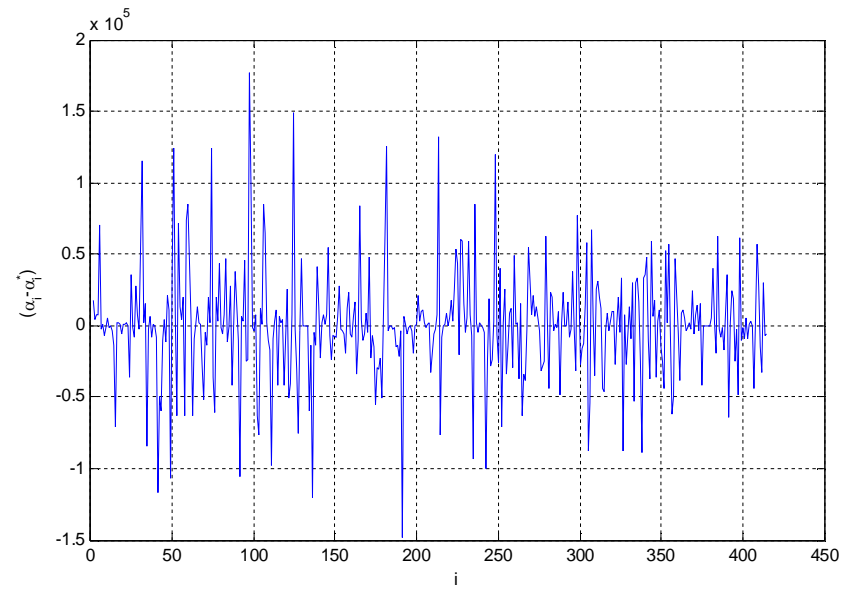

Gambar 4 Grafik Nilai $\left(\alpha_{i}-\alpha_{i}^{*}\right)$ terhadap $i$

Pada Gambar 4 terlihat hubungan antara nilai $\left(\alpha_{i}-\alpha_{i}^{*}\right)$ terhadap $x$. jumlah nilai $\left(\alpha_{i}-\alpha_{i}^{*}\right)$ sama dengan jumlah data training, yaitu sebanyak 415 data. Nilai $\left(\alpha_{i}-\alpha_{i}^{*}\right)$ bersifat fluktuatif terhadap nilai $x$ karena $\left(\alpha_{i}-\alpha_{i}^{*}\right)$ merupakan penggambaran dari model yang digunakan dan model yang digunakan bersifat fluktuatif. Nilai $\left(\alpha_{i}-\alpha_{i}^{*}\right)$ akan digunakan sebagai parameter model prediksi $f(x)$. Nilai minimum dan maksimum dari nilai $\left(\alpha_{i}-\alpha_{i}^{*}\right)$ yang didapatkan adalah -147.930 dan 176.600.

Setelah nilai $\left(\alpha_{i}-\alpha_{i}^{*}\right)$ didapatkan, maka model SVR dapat dihitung menggunakan Persamaan (15). Model yang telah dibentuk akan digunakan untuk memprediksi nilai $y$ data training dan nilai $y$ data testing. Gambar 5 merupakan grafik hasil prediksi dari model SVR dan pencocokan antara data aktual dan data hasil prediksi untuk data training yaitu sebanyak 415 data: 


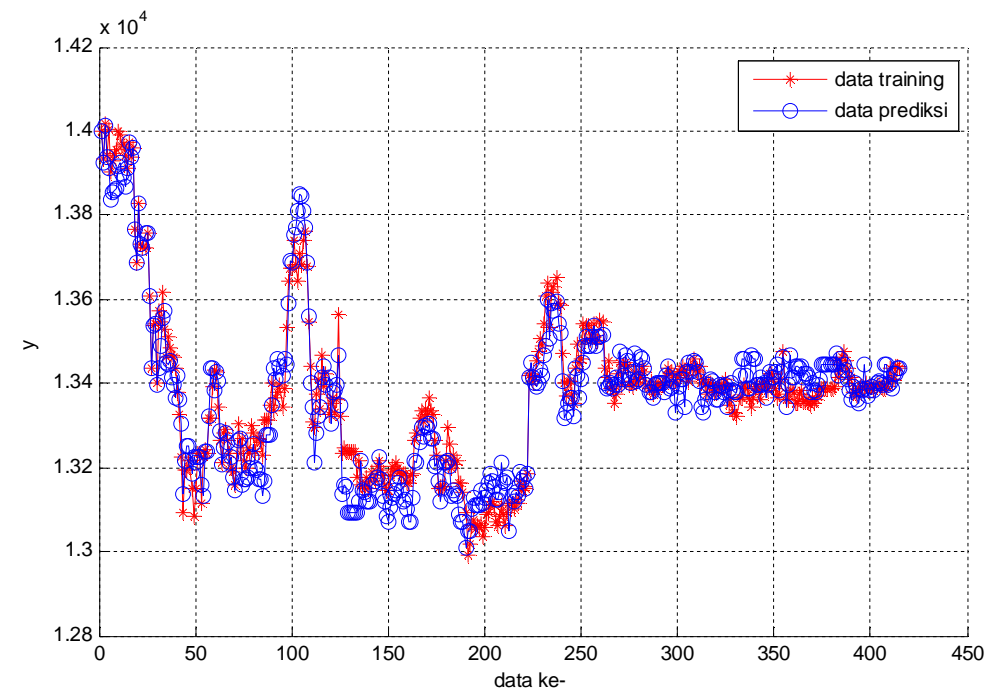

Gambar 5 Grafik $y_{\text {training }}$ dan Nilai Prediksi terhadap $x$ (SVR)

Pada Gambar 5 terlihat hubungan antara $y_{\text {training }}$ dan nilai prediksi terhadap $x$. Terlihat bahwa prediksi model SVR terhadap data training baik, hal ini disebabkan karena nilai $y_{\text {training }}$ digunakan untuk mencari nilai $\left(\alpha_{i}-\alpha_{i}^{*}\right)$, namun tidak semua kasus dengan model SVR dapat memprediksi dengan baik data aktual, hal tersebut bergantung pada pemilihan nilai toleransi dan pemilihan kernel. Seperti pada penelitian ini nilai toleransi yang digunakan adalah sebesar 0,1. Nilai RMSE terhadap nilai aktual pada grafik tersebut adalah sebesar 54,3156, yang menandakan bahwa error yang didapatkan cukup kecil (nilai prediksi mengandung kesalahan sekitar 54,3156 rupiah), berarti hasil prediksi cukup baik. Nilai $\mathrm{R}^{2}$ antara nilai prediksi dan nilai aktual adalah 0,9223 , hal ini menandakan nilai prediksi memiliki pola yang sangat sesuai dengan nilai aktual.

Model $f(x)$ dengan nilai $\mathrm{b}=0, \sigma=\frac{1}{\sqrt{2}}$ nilai parameter $K\left(x_{i}, x\right)$ dan $\left(\alpha_{i}-\alpha_{i}^{*}\right)$ didapatkan dengan menggunakan data training yaitu sebanyak 415 akan digunakan untuk memprediksi data testing dengan cara sebagai berikut :

$$
\begin{aligned}
f(x)=\boldsymbol{w}^{T} \boldsymbol{\varphi}(x)= & \sum_{i=1}^{415}\left(\alpha_{i}-\alpha_{i}^{*}\right) K\left(x_{i}, x\right) \\
= & \left(\alpha_{1}-\alpha_{1}^{*}\right) K\left(x_{1}, x\right)+\left(\alpha_{2}-\alpha_{2}^{*}\right) K\left(x_{2}, x\right)+\cdots+\left(\alpha_{415}-\alpha_{415}^{*}\right) K\left(x_{415}, x\right) \\
= & \left(\alpha_{1}-\alpha_{1}^{*}\right) \exp \left(-\frac{\left\|x_{1}-x\right\|}{2 \sigma^{2}}\right)+\left(\alpha_{2}-\alpha_{2}^{*}\right) \exp \left(-\frac{\left\|x_{2}-x\right\|}{2 \sigma^{2}}\right) \\
& +\left(\alpha_{415}-\alpha_{415}^{*}\right) \exp \left(-\frac{\left\|x_{415}-x\right\|}{2 \sigma^{2}}\right)
\end{aligned}
$$

dengan $x$ merupakan $x$ yang telah diZ-Scorekan dan dapat dilihat pada Gambar 2 dan $n$ adalah jumlah data training.

Berdasarkan pemodelan SVR didapat nilai RMSE terhadap data aktual sebesar 66,8015. Hal ini menandakan bahwa nilai error cukup kecil, berarti hasil prediksi cukup baik. Nilai $\mathrm{R}^{2}$ antara nilai prediksi dan nilai testing adalah 0,5397. Hal tersebut menunjukkan bahwa ketepatan hasil model pada metode SVR berada di atas nilai $50 \%$. 
Tabel 1 Tabel Prediksi Nilai Tukar Jual Harian Dolar Amerika terhadap Rupiah dengan Metode SVR (dalam satuan rupiah)

\begin{tabular}{cccccc}
\hline $\begin{array}{c}\text { Data } \\
\text { ke }-\end{array}$ & $\begin{array}{c}\text { Hasil } \\
\text { Prediksi }\end{array}$ & $\begin{array}{c}\text { Data } \\
\text { ke }-\end{array}$ & $\begin{array}{c}\text { Hasil } \\
\text { Prediksi }\end{array}$ & $\begin{array}{c}\text { Data } \\
\text { ke - }\end{array}$ & $\begin{array}{c}\text { Hasil } \\
\text { Prediksi }\end{array}$ \\
\hline 416 & 13.384 & 426 & 13.445 & 436 & 13.202 \\
417 & 13.412 & 427 & 13.411 & 437 & 13.268 \\
418 & 13.402 & 428 & 13.329 & 438 & 13.220 \\
419 & 13.360 & 429 & 13.366 & 439 & 13.337 \\
420 & 13.474 & 430 & 13.406 & 440 & 13.337 \\
421 & 13.425 & 431 & 13.348 & 441 & 13.471 \\
422 & 13.402 & 432 & 13.183 & 442 & 13.390 \\
423 & 13.425 & 433 & 13.161 & 443 & 13.425 \\
424 & 13.462 & 434 & 13.179 & 444 & 13.418 \\
425 & 13.445 & 435 & 13.249 & 445 & 13.527 \\
\hline
\end{tabular}

\section{PENUTUP}

Berdasarkan hasil penelitian yang dibahas pada bab sebelumnya, dapat ditarik kesimpulan bahwa pada kasus prediksi nilai tukar dolar terhadap rupiah untuk mengestimasi parameter model pada metode SVR, $b$ yang dipilih dalam model bernilai nol $(b=0)$, dengan menggunakan data traning didapatkan

model SVR dengan persamaan $f(x)=\sum_{i=1}^{415}\left(\alpha_{i}-\alpha_{i}^{*}\right) K\left(x_{i}, x\right)$ dengan nilai parameter $\left(\alpha_{i}-\alpha_{i}^{*}\right)$ dan $K\left(x_{i}, x\right)$ yang bervariasi. Hasil prediksi dari data training yang merupakan data nilai tukar jual dolar Amerika terhadap rupiah dari tanggal 5 Januari 2016 sampai 18 Agustus 2017 yaitu sebanyak 415 data dengan menggunakan metode SVR sudah baik. Hal ini terlihat dari pemodelan data training dengan nilai $\mathrm{R}^{2}$ bernilai 0,9223 dan RMSE bernilai 54,3156 (nilai prediksi mengandung kesalahan sekitar 54,3156 rupiah). Estimasi parameter model yang didapatkan dari data training yang digunakan untuk memprediksikan data testing yaitu sebanyak 30 data, juga memperlihatkan hasil yang cukup baik dengan nilai $\mathrm{R}^{2}$ bernilai 0,5397 dan RMSE bernilai 66,8015 (nilai prediksi mengandung kesalahan sekitar 66,8015 rupiah).

\section{DAFTAR PUSTAKA}

[1]. Meesad, P. dan Rasel, R.I. Predicting Stock Market Price Using Support Vector Regression. In ICIEV. 2013.

[2]. Rusmalawati, V., Furqon, M. dan Indriati. Peramalan Harga Saham Menggunakan Metode Support Vector Regression (SVR) dengan Particle Swarm Optimization (PSO). Pengembangan Teknologi Informasi dan Komputer. 2017; 2(5):1980-1990.

[3]. Amanda, R., Yasin, H. dan Prahutama, A. Analisis Support Vector Regression (SVR) dalam Memprediksi Kurs Rupiah terhadap Dollar Amerika Serikat. GAUSSIAN. 2014; 3(4):849-57.

[4]. Bermolen, P. dan Rossi, D. Support Vector Regression for Link Load Prediction. In IEEE Xplore. 2008.

[5]. Yulianto, T., Kuzairi dan Hasanah, R. Implementasi Metode Lagrange untuk Optimasi Penyakit Kanker Hati. UJMC. 2016; 2(1):62-68.

[6]. Septiningrum, L., Yasin, H. dan Sugito. Prediksi Indeks Harga Saham Gabungan Menggunakan Support Vector Regression (SVR) dengan Algoritma Grid Search. GAUSSIAN. 2015; 4(2):315-321.

[7]. Putrodjojo, G. dan Rahardja, U. Matematika Ekonomi. Jakarta: 2015. 
[8]. Lin, C.-J. Machine Learning Software: Design and Practical Use. Kyoto: Machine Learning Summer School. 2012.

[9]. Chang, Y.-W. et al., 2010. Training and Testing Low-Degree Polynomial Data Mappings Via Linear SVM. Machine Learning Research. 2010; 11:1471-1490.

[10]. Susanto. DIGLIB UNNES. [Online] Available at: http://lib.unnes.ac.id/990/ [Accessed 6 June 2018]. 2007.

[11]. Smola, A.J. \& Scholkopf, B. A Tutorial on Support Vector Regression. Statistics and Computing Kluwer Academic Pub. 2004; 14:199-222.

[12]. Adiningtyas, D.T., Safitri, D. dan Mukid, M.A. Peramalan Jumlah Tamu Hotel di Kabupaten Demak Menggunakan Metode Support Vector Regression. GAUSSIAN. 2015; 4(4):785-94.

[13]. Cheadle, C., Vawter, M.P., Freed, W.J. dan Becker, K.J. Analysis of Microarray Data using Z Score Transformation. Journal of Molecular Diagnostics. 2003; 5(2).

[14]. Bhartendu. Mathwork. [Online] Available at: https://www.mathworks.com/matlabcentral/fileexchange/63060-support-vector-regression [Accessed 1 March 2018]. 2017.

[15]. Suryaningrum, K.M. dan Wijaya, S.P. Analisa dan Penerapan Metode Single Exponential Smoothing untuk Prediksi Penjualan pada Periode Tertentu. In Prosiding SNATIF Ke-2. 2015.

[16]. Gujarati, D.N. Dasar-dasar Ekonometrika. Jakarta:2003.

[17]. Anonim. Bank Indonesia. [Online] Available at: https://www.bi.go.id/id/moneter/informasikurs/referensi-jisdor/Default.aspx [Accessed 5 August 2017]. 2017.

$\begin{array}{lc}\text { SRIYANA } & \begin{array}{c}\text { Jurusan Matematika FMIPA UNTAN, Pontianak } \\ \text { sriyana39@ student.untan.ac.id }\end{array} \\ \text { SHANTIKA MARTHA } & \begin{array}{c}\text { Jurusan Matematika FMIPA UNTAN, Pontianak } \\ \text { shantika.martha@ math.untan.ac.id } \\ \text { : Jurusan Matematika FMIPA UNTAN, Pontianak } \\ \text { evysulistianingsih@ math.untan.ac.id }\end{array}\end{array}$

